\section{JURNAL EKONOMI EFEKTIF}

ISSN : $2622-8882$, E-ISSN : 2622-9935

Jurnal Ekonomi Efektif, Vol. 3, No. 2, Januari 2021 @Prodi Manajemen Fakultas Ekonomi Universitas Pamulang

\title{
PENGARUH PEMBERIAN INSENTIF TERHADAP KINERJA KARYAWAN PADA PT. ASURANSI SINARMAS CABANG BEKASI
}

\author{
Mitri Nelsi \\ Universitas Pamulang, Tangerang Selatan, Banten, Indonesia \\ dosen02493@unpam.ac.id
}

Manuskrip: Nov-2020; Ditinjau: Des-2020; Diterima: Des-2020; Online: Jan-2021; Diterbitkan: Jan-2021

\begin{abstract}
ABSTRAK
Penelitian ini bertujuan untuk mengetahui pengaruh Pemberian Insentif terhadap kinerja karyawan pada PT Asuransi Sinarmas Cabang Bekasi. Metode yang digunakan adalah explanatory research dengan sampel sebanyak 67 responden. Teknik analisis menggunakan analisis statistik dengan pengujian regresi, korelasi, determinasi dan uji hipotesis. Hasil penelitian ini variabel Pemberian Insentif diperoleh nilai rata-rata skor sebesar 3,733 dengan kriteria baik. Variabel kinerja karyawan diperoleh nilai rata-rata skor sebesar 3,776 dengan kriteria baik. Pemberian Insentif berpengaruh positif dan signifikan terhadap kinerja karyawan dengan nilai persamaan regresi $\mathrm{Y}=12,188+0,685 \mathrm{X}$, dan nilai koefisien korelasi 0,792 atau memiliki tingkat hubungan yang kuat dengan nilai determinasi $62,7 \%$. Uji hipotesis diperoleh signifikansi $0,000<0,05$.
\end{abstract}

Kata Kunci: Pemberian Insentif, Kinerja Karyawan.

\begin{abstract}
This study aims to determine the effect of Incentives on employee performance at PT Asuransi Sinarmas Bekasi Branch. The method used is explanatory research with a sample of 67 respondents. The analysis technique uses statistical analysis with regression testing, correlation, determination and hypothesis testing. The results of this study, the variable of Incentives, obtained an average score of 3.733 with good criteria. Employee performance variables obtained an average score of 3.776 with good criteria. Incentives have a positive and significant effect on employee performance with the regression equation $Y=12.188+0.685 X$, and a correlation coefficient value of 0.792 or having a strong level of relationship with a determination value of $62.7 \%$. Hypothesis testing obtained a significance of $0.000<0.05$..
\end{abstract}

Keywords: Providing Incentives, Employee Performance. 


\section{PENDAHULUAN}

\section{A. Latar Belakang Masalah}

Sumber daya manusia merupakan suatu objek yang sangat penting untuk dibicarakan, karena sumber daya manusia mempunyai peranan yang dapat mengarahkan, mengelola dan melaksanakan segala aktivitas perusahaan, tanpa adanya sumber daya manusia dalam suatu organisasi perusahaan, berarti tidak ada pula kegiatan dan tersebut. Oleh sebab itulah diperlukan cara dan upaya untuk mendorong atau merangsang setiap tenaga kerja agar bekerja seoptimal mungkin sesuai bidang tugasnya masing-masing.

Persaingan dunia usaha saat ini semakin kompetitif, karena itu setiap perusahaan harus mampu mengatur dan mengolah semua sumber daya yang dimilikinya dengan efektif dan efisien agar tetap dapat bertahan hidup dan berkembang. Salah satu contoh dari sumber daya perusahaan tersebut adalah tenaga kerja atau karyawan.Setiap perusahaan pasti mengharapkan tenaga kerja atau karyawannya memberikan hasil yang maksimal di dalam bekerja. Hal ini dapat dilihat dari hasil kinerja yang tinggi. Oleh karena itu perusahaan harus berusaha melakukan tindakan- tindakan yang menyebabkan tenaga kerja atau karyawannya mau mewujudkan harapan tersebut. Salah satu upaya yang dapat dilakukan oleh perusahaan adalah dengan mencari tahu faktor-faktor apa yang mempengaruhi kinerja karyawan tersebut, kemudian mengambil tindakan untuk meningkatkan kinerja karyawannya.

Ada beberapa alasan penulis tertarik melakukan penelitian di PT. Asuransi Sinarmas karena, PT. Asuransi Sinarmas merupakan salah satu perusahaan terbesar di indonesia, pastinya terdapat berbagai macam divisi yang menerapkan sistem insentif kepada karyawannya untuk mencapai target dalam kinerjanya. Berikut penulis sampaikan data inputan pertahun untuk periode (2016-2019) sebagai berikut:

Tabel 1. Data Inputan Data Entry Divisi Branch Admin Support PT Asuransi Sinarmas Cabang Bekasi Periode (2016-2019).

\begin{tabular}{|c|c|c|c|c|}
\hline \multirow{2}{*}{ Tahun } & \multicolumn{2}{|c|}{ Data Inputan } & Polis di Input & Total HLL \\
\cline { 2 - 5 } & $(\mathrm{Rp})$ & (USD) & & \\
\hline 2016 & 153.546 .789 .892 & 90.049 .688 & 12.543 .980 & 2.250 .765 .900 \\
\hline 2017 & 209.456 .294 .320 & 111.987 .230 & 14.542 .579 & 1.097 .764 .896 \\
\hline 2018 & 289.409 .962 .250 & 112.243 .100 & 14.800 .520 & 900.544 .088 \\
\hline 2019 & 108.650 .356 .239 & 89.896 .765 & 11.350 .301 & 2.987 .578 .022 \\
\hline
\end{tabular}

Berdasarkan data pada tabel di atas, Data Inputan ( IDR ) adalah data Pembayaran nasabah di Rekening Koran yang masuk rekening PT Asuransi sinarmas yang telah di input dalam bentuk ( IDR ) oleh Data Entry BAS jumlahnya fluktuatif. Data Inputan (USD) adalah data Pembayaran nasabah di Rekening Koran yang masuk rekening PT Asuransi sinarmas yang telah di input dalam bentuk (IDR) oleh Data Entry BAS jumlahnya fluktuatif. Polis Yang Di Input Adalah Total jumlah Polis yang di input oleh data enty BAS jumlahnya fluktuatif. Total HLL (Hutang Lain-lain) adalah Dana masuk nasabah yang yang melakukan pembayaran di rekening Asuransi Sinarmas yag tidak dapat teridentifikasi, dengan kata lain akan menjadi beban perusahaan dalam melunasi pembayaran yang ada di rekening koran jumlahnya fluktuatif. Dari tabel diatas dapat dilihat data tahun 2016-2019 data dana masuk yang diproses mengalami penurunan dengan kata lain HLL akan meningkat.

Dengan alasan di atas, penulis merasa tertarik untuk mengadadakan penelitian yang berkaian dengan pengaruh insentif terhadap kinerja karyawan. Oleh karena itu penulis menentukan judul "Pengaruh Pemberian Insentif Terhadap Kinerja Karyawan Pada PT. Asuransi Sinar Mas Cabang Bekasi“" 


\section{B. Rumusan Masalah}

1. Bagaimana Pemberian Insentif pada PT Asuransi Sinarmas Cabang Bekasi ?.

2. Bagaimana kinerja karyawan pada PT Asuransi Sinarmas Cabang Bekasi ?.

3. Adakah pengaruh antara Pemberian Insentif terhadap kinerja karyawan pada PT Asuransi Sinarmas Cabang Bekasi ?.

\section{Tujuan Penelitian}

1. Untuk mengetahui kondisi Pemberian Insentif pada PT Asuransi Sinarmas Cabang Bekasi.

2. Untuk mengetahui kondisi kinerja karyawan pada PT Asuransi Sinarmas Cabang Bekasi.

3. Untuk mengetahui pengaruh antara Pemberian Insentif terhadap kinerja karyawan pada PT Asuransi Sinarmas Cabang Bekasi.

\section{METODE PENELITIAN}

\section{Populasi}

Populasi dalam penelitian ini berjumlah 67 responden PT Asuransi Sinarmas Cabang Bekasi

\section{Sampel}

Teknik pengambilan sampling dalam penelitian ini adalah sampel jenuh, dimana semua anggota populasi dijadikan sebagai sampel. Dengan demikian sampel dalam penelitian ini sampel yang digunakan berjumlah 67 responden.

\section{Jenis Penelitian}

Jenis penelitian yang dipakai adalah asosiatif, dimana tujuannya adalah untuk mengetahui atau mencari keterhubungan antara variabel independen terhadap variabel dependennya

\section{Metode Analisis Data}

Dalam menganalisis data digunakan uji validitas, uji reliabilitas, analisis regresi linier sederhana, analisis koefisien korelasi, analisis koefisien determinasi dan pengujian hipotesis.

\section{HASIL PENELITIAN DAN PEMBAHASAN}

\section{Analisis Deskriptif}

Pada pengujian ini digunakan untuk mengetahui skor minimum dan maksimum skor tertinggi, ratting score dan standar deviasi dari masing-masing variabel. Adapun hasilnya sebagai berikut:

Tabel 2. Hasil Analisis Descriptive Statistics

Descriptive Statistics

$\mathrm{N}$ Minimum Maximum Mean Std. Deviation

\begin{tabular}{|l|l|l|l|l|l|l|}
\hline Pemberian Insentif (X) & 80 & 28 & 44 & 34.00 & 4.016 \\
\hline Kinerja Karyawan (Y) & 80 & 29 & 49 & 38.11 & 4.183 \\
\hline Valid N (listwise) & 80 & & & & \\
\hline
\end{tabular}

Pemberian Insentif diperoleh varians minimum sebesar 29 dan varians maximum 49 dengan ratting score sebesar 3,733 dengan standar deviasi 4,019. Skor ini termasuk pada rentang sakala 3,40-4,19 dengan kriteria baik atau setuju.

Kinerja karyawan diperoleh varians minimum sebesar 29 dan varians maximum 48 dengan ratting score sebesar 3,776 dengan standar deviasi 4,083. Skor ini termasuk pada rentang sakala 3,40-4,19 dengan kriteria baik atau setuju.. 


\section{Analisis Verifikatif.}

Pada analisis ini dimaksudkan untuk mengetahui pengaruh variabel independen terhadap variabel dependen. Adapun hasil pengujian sebagai berikut:

\section{a. Analisis Regresi Linier Sederhana}

Uji regresi ini dimaksudkan untuk mengetahui perubahan variabel dependen jika variabel independen mengalami perubahan. Adapun hasil pengujiannya sebagai berikut:

Tabel 3. Hasil Pengujian Regresi Linier Sederhana

\section{Coefficients $^{\mathrm{a}}$}

Unstandardized

Coefficients

\begin{tabular}{lr|r|r|r|r} 
Model & \multicolumn{1}{c}{ B } & Std. Error & Beta & \multicolumn{1}{c}{ t } & \multicolumn{1}{c}{ Sig. } \\
\hline 1 (Constant) & 12.188 & 2.468 & & 4.939 & .000 \\
\hline Pemberian Insentif $(\mathrm{X})$ & .685 & .066 & .792 & 10.444 & .000 \\
\hline
\end{tabular}

Berdasarkan hasil pengujian pada tabel di atas, diperoleh persamaan regresi $\mathrm{Y}$

$=12,188+0,685 \mathrm{X}$. Dari persamaan tersebut dijelaskan sebagai berikut:

1) Konstanta sebesar 12,188 diartikan jika Pemberian Insentif tidak ada, maka telah terdapat nilai kinerja karyawan sebesar 12,188 point.

2) Koefisien regresi Pemberian Insentif sebesar 0,685, angka ini positif artinya setiap ada peningkatan Pemberian Insentif sebesar 0,685 point maka kinerja karyawan juga akan mengalami peningkatan sebesar 0,685 point. .

\section{b. Analisis Koefisien Korelasi}

Analisis koefisien korelasi dimaksudkan untuk mengetahui tingkat kekuatan hubungan dari variabel independen terhadap variabel dependen. Adapun hasil pengujian sebagai berikut:

Tabel 4. Hasil Pengujian Koefisien Korelasi Pemberian Insentif Terhadap Kinerja

Karyawan..

Correlationsb

\begin{tabular}{|c|c|c|c|}
\hline & & Motivasi (X1) & Kinerja Karyawan $(\mathrm{Y})$ \\
\hline \multirow[t]{2}{*}{ Pemberian Insentif (X) } & Pearson Correlation & 1 & $.767^{* *}$ \\
\hline & Sig. (2-tailed) & & .000 \\
\hline \multirow[t]{2}{*}{ Kinerja Karyawan (Y) } & Pearson Correlation & $.767^{* * *}$ & 1 \\
\hline & Sig. (2-tailed) & .000 & \\
\hline
\end{tabular}

Berdasarkan hasil pengujian diperoleh nilai korelasi sebesar 0,792 artinya Pemberian Insentif memiliki hubungan yang kuat terhadap kinerja karyawan.

\section{c. Analisis Koefisien Determinasi}

Analisis koefisien determinasi dimaksudkan untuk mengetahui besarnya persentase pengaruh dari variabel independen terhadap variabel dependen. Adapun hasil pengujian sebagai berikut:

Tabel 5. Hasil Pengujian Koefisien Determinasi Pemberian Insentif Terhadap

$$
\text { Kinerja Karyawan. }
$$

Model Summary

\begin{tabular}{lc|r|r|r} 
Model & R & R Square & Adjusted R Square & Std. Error of the Estimate \\
\hline 1 & $.792^{\mathrm{a}}$ & .627 & .621 & 2.514 \\
\hline
\end{tabular}

Berdasarkan hasil pengujian diperoleh nilai determinasi sebesar 0,627 artinya Pemberian Insentif memiliki kontribusi pengaruh sebesar $62,7 \%$ terhadap kinerja karyawan, sedangkan sisanya sebesar 37,3\% dipengaruhi oleh faktor lain yang tidak dilakukan penelitian. 


\section{d. Uji Hipotesis}

Pengujian hipotesis dengan uji t digunakan untuk mengetahui hipotesis mana yang diterima. Rumusan hipotesis: Terdapat pengaruh yang signifikan antara Pemberian Insentif terhadap kinerja karyawan.

Tabel 6. Hasil Uji Hipotesis Pemberian Insentif Terhadap Kinerja Karyawan.

Coefficients $^{\mathrm{a}}$

\begin{tabular}{|c|c|c|c|c|c|}
\hline \multirow[b]{2}{*}{ Model } & \multicolumn{2}{|c|}{$\begin{array}{l}\text { Unstandardized } \\
\text { Coefficients }\end{array}$} & \multirow{2}{*}{$\begin{array}{c}\text { Standardized } \\
\text { Coefficients } \\
\text { Beta } \\
\end{array}$} & \multirow[t]{2}{*}{$\mathrm{t}$} & \multirow[t]{2}{*}{ Sig. } \\
\hline & $\mathrm{B}$ & Std. Error & & & \\
\hline 1 (Constant) & 12.188 & 2.468 & & 4.939 & .000 \\
\hline $\begin{array}{l}\text { Pemberian Insentif } \\
(\mathrm{X})\end{array}$ & .685 & .066 & .792 & 10.444 & .000 \\
\hline
\end{tabular}

Berdasarkan hasil pengujian pada tabel di atas, diperoleh nilai t hitung $>\mathrm{t}$ tabel atau $(10,444>1,997)$, dengan demikian hipotesis yang diajukan bahwa terdapat pengaruh yang signifikan atara Pemberian Insentif terhadap kinerja karyawan diterima.

\section{PEMBAHASAN HASIL PENELITIAN}

\section{Kondisi Jawaban Responden Variabel Pemberian Insentif}

Berdasarkan jawaban responden, variabel Pemberian Insentif diperoleh ratting score sebesar 3,733 berada di rentang skala 3,40 - 4,19 dengan kriteria baik atau setuju.

\section{Kondisi Jawaban Responden Variabel Kinerja Karyawan}

Berdasarkan jawaban responden, variabel kinerja karyawan diperoleh ratting score sebesar 3,776 berada di rentang skala 3,40 - 4,19 dengan kriteria baik atau setuju.

\section{Pengaruh Pemberian Insentif Terhadap Kinerja Karyawan}

Pemberian Insentif berpengaruh signifikan terhadap kinerja karyawan dengan persamaan regresi $\mathrm{Y}=12,188+0,685 \mathrm{X}$, nilai korelasi sebesar 0,792 atau memiliki hubungan yang kuat dengan kontribusi pengaruh sebesar 62,7\%. Pengujian hipotesis diperoleh nilai $t$ hitung $>\mathrm{t}$ tabel atau $(10,444>1,997)$. Dengan demikian hipotesis yang diajukan bahwa terdapat berpengaruh signifikan antara Pemberian Insentif terhadap kinerja karyawan diterima. 


\section{PENUTUP}

\section{Kesimpulan}

a. Variabel Pemberian Insentif diperoleh ratting score sebesar 3,733 berada di rentang skala 3,40-4,19 dengan kriteria baik atau setuju.

b. Variabel kinerja karyawan diperoleh ratting score sebesar 3,776 berada di rentang skala 3,40-4,19 dengan kriteria baik atau setuju.

c. Pemberian Insentif berpengaruh signifikan terhadap kinerja karyawan dengan persamaan regresi $\mathrm{Y}=12,188+0,685 \mathrm{X}$, nilai korelasi sebesar 0,792 atau kuat dan kontribusi pengaruh sebesar $62,7 \%$ sedangkan sisanya sebesar $37,3 \%$ dipengaruhi faktor lain. Uji hipotesis diperoleh nilai $t$ hitung $>t$ tabel atau $(10,444>1,997)$.

\section{Saran}

a. Insentif dapat menigkatkan motivasi kerja karyawan. Oleh karena itu PT Asuransi Sinarmas Kantor Pusat Tanah Abang dalam memberikan insentif yang lebih baik lagi kepada karyawan yang berprestasi sehingga dapat memberikan dorongan kerja kepada karyawan yang belum berprestasi untuk lebih meningkatkan kinerjanya.

b. Untuk dapat meningkatkan kinerja karyawan BAS maka pemimpin perlu mengadakan perbaikan sistem pada penghargaan prestasi dalam kinerja karyawan yang sesuai dengan sistem insentif yang memperhitungkan beban kerja serta tanggung jawab yang dipegang. Dengan pemberian kesempatan yang memadai dan berkelanjutan untuk pendidikan dan pelatihan bagi seluruh karyawan sehingga dengan begitu kinerja karyawan akan menjadi semakin meningkat.

\section{DAFTAR PUSTAKA}

Agus, Tulus. 2002. Manajemen Sumber Daya Manusia. Jakarta: PT. Gramedia Pustaka Utama.

Alex, S. Nitisemito. 2006. Manajemen Personalia. Cetakan Kesembilan ( Edisi Ketiga). Jakarta: Ghalia

Anwar Prabu Mangkunegara. 2011. Manajemen Sumber Daya Manusia Perusahaan. Bandung: PT. Remaja Rosda Karya

Arikunto, Suharsimi. 2004. Prosedur Penelitian Suatu Pendekatan Praktek. Jakarta: Rineka Cipta

Bambang Wahyudi. 2011. Manajemen Sumber Daya Manusia. Bandung: Penerbit Sulita

Chris Rowley dan Keith Jackson. 2012. Manajemen Sumber Daya Manusia. Jakarta: PT.Raja Grafindo Persada

Dessler, Gary. 2009. Manajemen SDM. buku 1. Jakarta: Indeks

Erlangga, H. (2019). The Meaning, Benefit and Importance of Development Entrepreneurship in Higher Education. Asian Journal of Contemporary Education, $3(2), 105-110$.

Esposito, Jean E. 2003. Membangun Pengertian di tempat kerja. Jakarta: Prestasi Pustaka F.X. Urip, dkk,2013. Mengatasi Krisis Manusia di Perusahaan. Jakarta: Grasindo

Gomes, Faustino Cardoso, Dr. 2012. MSDM. Yogyakarta: Erlangga

Gunartin, G., Mulyanto, E., \& Sunarsi, D. (2020). The Role Analysis of Waste Bank in Improving the Community's Creative Economy (Study at Ketumbar Pamulang Waste Bank). Budapest International Research and Critics Institute (BIRCI-Journal): Humanities and Social Sciences, 3(4), 3262-3269.

Handoko T H. 2012. Manajemen Personalia dan Sumber Daya Manusia. Edisi 2. Yogyakarta: BPFE

Hasibuan, M.S.P. 2011. Manajemen Sumber Daya Manusia. EdisiRevisi. Jakarta: PT 
Bumi Aksara.

Husein Umar. 2012. Evaluasi Kinerja Perusahaan. Jakarta: Gramedia Pustaka Utama.

Husein Umar. 2012. Petunjuk Lengkap Membuat Skripsi Dan Tesis. Jakarta: Rajawali Pers.

IvancevichJohn.M,dkk. 2008. Perilaku dan Manajemen Organisasi. Jakarta: Erlangga.

Khoiri, A., Kusumawati, I., Kahar, M. S., \& Mursidi, A. (2019, February). Analysis of three representations in problem solving on additional relativistic velocities. In Journal of Physics: Conference Series (Vol. 1153, No. 1, p. 012136). IOP Publishing

Kreitner, Robert dan Kinicki, Angelo. 2008. Perilaku Organisasi. buku 1 dan 2. Jakarta: Salemba Empat.

Malayu S. P Hasibuan.2013. Manajemen Sumber Daya Manusia. Edisi revisi ke Enam. Bandung: Indek

Malayu S.P Hasibuan. 2005. Manajemen Sumber Daya Manusia. Edisi revisi Bumi Aksara. Jakarta: Grasindo.

Mangkunegara, A.A.A.P. 2011. Manajemen Sumber Daya Manusia Perusahaan. Bandung: Remaja Rosda karya.

Manullang M \& Manullang M. 2005. Manajemen Sumber Daya Manusia. (edisi-1). Yogyakarta : BPFE-Yogyakarta.

Marihot Tua Efendi Hariandja. 2005. Manajemen Sumber Daya Manusia. Jakarta: Penerbit PT. Gramedia Widia Sarana Indonesia.

Mathis, Robert L. dan John H. Jackson. 2011. Manajemen Sumber Daya Manusia. Edisi Pertama. Jakarta: Salemba Empat.

Rivai, V. 2004. Manajemen Sumber Daya Manusia untuk Perusahaan Dari Teori ke Praktek. Jakarta: PT Raja Grafindo Perkasa.

Robbins \& Coulter. 2011. Manajemen. Jakarta: Indeks.

Rozi, A., Agustin, F., Hindriari, R., Rostikawati, D., \& Akbar, I. R. (2020). The Effect Of Leadership On Employee Performance at PT. Stella Satindo In Jakarta. HUMANIS (Humanities, Management and Science Proceedings), 1(1).

Ruky., Ahmad. 2003. Sistem Manajemen Kinerja. Jakarta: Gramedia Pustaka Utama.

Sadili Samsudin. 2005. Manajemen Sumber Daya Manusia. Bandung: Pustaka Setia.

Sarwani, S., Akbar, I. R., Handoko, A. L., \& Ilham, D. (2020). Pengaruh Pelatihan dan Motivasi terhadap Produktivitas Kerja Karyawan pada PT. Lion Mentari Airlines Bandara Internasional Soekarno Hatta Cengkareng. Jurnal Ilmu Komputer dan Bisnis, 11(2a), 91-100.

Sarwono, Jonathan. 2012. Metode Penelitian Kuantitatif dan Kualitatif. Yogyakarta: Graha Ilmu.

Sedarmayanti dan Hidayat ,Syarifudin. 2014. Metodologi Penelitian. Bandung: Mandar Maju.

Siagian P. Sondang. 2011. Manajemen SDM. Cet 16 . Jakarta: Bumi Aksara.

Simanjuntak, Payaman J. 2005. Manajemen dan Evaluasi Kerja. Jakarta: Lembaga Penerbit FEUI.

Sunarsi, D., Rohaeni, . N., Wulansari, . R., Andriani, . J., Muslimat, . A., Rialmi, . Z., Kustini, . E., Kristianti, . L. S., Rostikawati, . D., Effendy, . A. A., Purwanto, . A. \& Fahlevi, . M. (2020) Effect of e-Leadership Style, Organizational Commitment and Service Quality towards Indonesian School Performance. Systematic Reviews in Pharmacy, 11 (10), 472-481. doi:10.31838/srp.2020.10.71. 